\title{
O USO DE DROGAS VASOATIVAS EM TERAPIA INTENSIVA
}

\author{
THE USE OF VASOACTIVES DRUGS IN THE INTENSIVE CARE UNIT
}

Fátima Magro Ostini'; Paulo Antoniazzi' ${ }^{1}$ Antonio Pazin Filho'; Reinaldo Bestetti' Maria Camila M. Cardoso² \& Anibal Basile-Filho ${ }^{3}$

\begin{abstract}
${ }^{1}$ Médicos Intensivistas da Unidade de Terapia Intensiva da Unidade de Emergência do Hospital das Clínicas; ${ }^{2}$ Médica Residente; ${ }^{3}$ Professor Assistente, Doutor e Chefe - Disciplina de Terapia Intensiva do Departamento de Cirurgia, Ortopedia e Traumatologia ${ }^{3}$ da Faculdade de Medicina de Ribeirão Preto da Universidade de São Paulo.

CorRespondÊncia: Prof.Dr. Anibal Basile-Filho - Disciplina de Terapia Intensiva, Departamento de Cirurgia, Ortopedia e Traumatologia da FMRPUSP - Hospital das Clínicas - 9 Andar- Campus Universitário - CEP: 14048-900 - Ribeirão Preto - SP. Fone: (016) 633-0836 ou 602-2593 - Email: abasile@.fmrp.usp.br.
\end{abstract}

OSTINI FM et al. O uso de drogas vasoativas em terapia intensiva. Medicina, Ribeirão Preto, 31: 400-411, jul./set. 1998.

RESUMO: Os autores apresentam uma revisão sucinta e objetiva dos principais agentes vasoativos, disponíveis atualmente para uso em terapia intensiva. Suas indicações, doses mais comumente utilizadas, efeitos adversos e cuidados com sua administração são abordados, objetivando-se o uso racional e criterioso desses preciosos auxiliares no tratamento de pacientes graves.

UNITERMOS: Catecolaminas. Vasodilatadores. Vasoconstritores. Unidade de Terapia Intensiva.

\section{INTRODUÇÃO}

Comumente empregadas nos pacientes graves, as drogas vasoativas são de uso corriqueiro nas unidades de terapia intensiva e o conhecimento exato da sua farmacocinética e farmacodinâmica é de vital importância para o intensivista, pois daí decorre o sucesso ou mesmo o insucesso de sua utilização.

O termo droga vasoativa é atribuído às substâncias que apresentam efeitos vasculares periféricos, pulmonares ou cardíacos, sejam eles diretos ou indiretos, atuando em pequenas doses e com respostas dose dependente de efeito rápido e curto, através de receptores situados no endotélio vascular ${ }^{(1)}$. Então, na maioria das vezes, é necessário o uso da monitorização hemodinâmica, invasiva, quando da utilização dessas substâncias, pois suas potentes ações determinam mudanças drásticas tanto em parâmetros circulatórios como respiratórios, podendo, do seu uso inadequado, advirem efeitos colaterais indesejáveis, graves e deletérios, que obrigam sua suspensão.

\section{DETERMINANTES DA OFERTA DE OXIGÊ- NIO $\left(\mathrm{DO}_{2}\right)$ AOS TECIDOS E DO DÉBITO CAR- DÍACO (DC)}

A perfusão tecidual e a oxigenação celular representam o mais importante objetivo da circulação, que é o suprimento do metabolismo corporal mesmo em condições não ideais. A oferta de oxigênio $\left(\mathrm{DO}_{2}\right)$ é a medida mais direta da função circulatória e o consumo de $\mathrm{O}_{2}\left(\mathrm{VO}_{2}\right)$ é a medida mais direta da atividade metabólica ${ }^{(2)}$. Imagina-se, então, que a distribuição inadequada de $\mathrm{O}_{2}$, em face da demanda metabólica, aumentada devido a fatores como trauma, perda de sangue e infecção, produzam hipoxemia tecidual, disfunção orgânica e morte.

As drogas vasoativas têm ação, principalmente, sobre os parâmetros que regulam o DC. Este é determinado pelo produto do volume sistólico (VS) e freqüência cardíaca (FC). O VS depende das pressões e dos volumes de enchimento ventricular (pré-carga), da contratilidade do miocárdio e da resistência ao esvaziamento ventricular (pós-carga), como pode ser visto na Figura 1. 


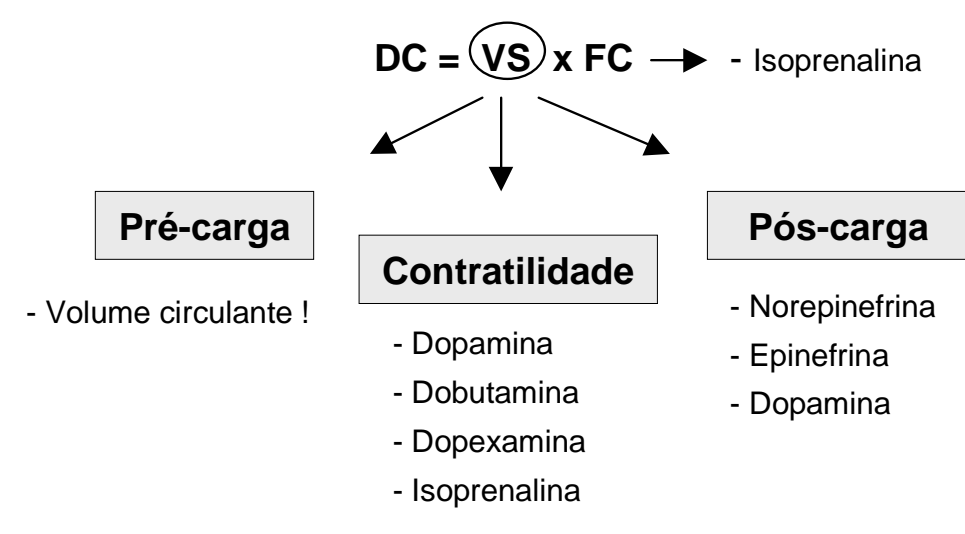

Figura 1 - Efeitos dos principais agentes simpatomiméticos sobre os parâmetros que regulam o débito cardíaco.

benzênico e uma cadeia lateral etilamina $^{(3)}$. Ocorre, no organismo, uma síntese natural e endógena de três catecolaminas: dopamina, adrenalina e noradrenalina. As catecolaminas endógenas originam-se da tirosina que se transforma sucessivamente em dopa, dopamina, noradrenalina e adrenalina por ação enzimática, em todos esses $\operatorname{passos}^{(4)}$. Sinteticamente são produzidas, além da adrenalina, noradrenalina e dopamina, três outras catecolaminas: dobutamina, isoproterenol e dopexamina. Todas essas aminas possuem indicações terapêuticas específicas, diferindo entre si pela seletividade e potência de ações

A FC é determinada pela capacidade de reação cronotrópica do coração à estimulação simpática, durante a reação de estresse. $\mathrm{A} \mathrm{DO}_{2}$ aos tecidos depende diretamente do DC e do conteúdo arterial de $\mathrm{O}_{2}\left(\mathrm{CaO}_{2}\right)$.

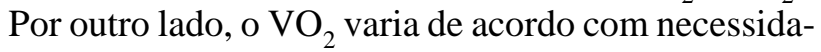
des metabólicas, sendo estas extremamente mutáveis e dependentes dos mecanismos envolvidos na agressão e integridade teciduais. $\mathrm{O}$ valor medido do $\mathrm{VO}_{2}$ pode ser obtido, à beira do leito, através da calorimetria indireta. Assim, o objetivo principal da utilização de drogas vasoativas é otimizar a relação $\mathrm{DO}_{2} / \mathrm{VO}_{2}$, distribuindo-se adequadamente o suprimento de $\mathrm{O}_{2}$ em face da demanda metabólica alterada dos diferentes órgãos e tecidos, na tentativa de se preservar a função bioquímica celular.

As drogas vasoativas mais empregadas são as catecolaminas, também denominadas aminas vasoativas ou drogas simpatomiméticas. Dentre elas, destacam-se a noradrenalina (NA), a adrenalina, a dopamina, a dopexamina, a dobutamina e o isoproterenol. Dispomos, também, da amrinone e dos vasodilatadores (nitroprussiato de sódio, nitratos, clorpromazina, prazozin, captopril, enalapril e bloqueadores de cálcio).

\section{AGENTES SIMPATOMIMÉTICOS}

As catecolaminas (adrenalina, noradrenalina, dopexamina, dopamina, isoproterenol e dobutamina) e drogas não catecolaminas (metaraminol, fenilefrina e metoxamina) são os agentes simpatomiméticos mais utilizados em terapia intensiva.

A substância básica da qual derivam as catecolaminas é a betafeniletilamina, que consiste num anel sobre os diferentes receptores. Existem ainda outras aminas simpatomiméticas (fenilefrina, metoxamina, anfetamina e efedrina), sem o núcleo "catecol", que agem através da liberação indireta de noradrenalina, desencadeando efeitos imprevisíveis, o que limita sua utilização.

As ações das catecolaminas são determinadas pelas suas ligações às três classes principais de receptores: alfa, beta e dopa. Os receptores (conceito puramente funcional) são glicoproteínas que se localizam na superfície da célula efetora e possuem estrutura molecular específica com a qual as moléculas de uma determinada substância, o mediador, reagem para causar uma resposta característica ou específica sobre a célula. Esses receptores, que são sensibilizados ou estimulados pelas catecolaminas, são denominados adrenérgicos por ter sido a adrenalina a primeira substância a ser evidenciada neste tipo de atividade. Atualmente, há conhecimento de dois subtipos para cada receptor estudado, possuindo estes distribuição, sensibilidade à substâncias farmacológicas e efeitos diferentes. Esses efeitos, exercidos pelas catecolaminas sobre os diversos receptores, podem ser visto na Tabela I.

\section{FATORES QUE REGULAM A DENSIDADE DE RECEPTORES NA MEMBRANA CELULAR}

Conforme pode ser visto na Tabela II, a densidade dos receptores adrenérgicos, na superfície celular, é dinâmica, podendo ser modulada por um grande número de doenças ou condições ${ }^{(5)}$. As mudanças na densidade dos receptores alteram significativamente 
Tabela I - Diferentes tipos de receptores, sua localização e efeitos

\begin{tabular}{|c|c|c|}
\hline Receptor & Localização & Efeito \\
\hline $\begin{array}{l}\text { DA } 1 \text { (dopaminérgico tipo 1) } \\
\text { Pós-sináptico }\end{array}$ & $\begin{array}{l}\text { Coração } \\
\text { Vasos } \\
\text { Rins }\end{array}$ & $\begin{array}{l}\text { Vasodilatação coronariana. } \\
\text { Vasodilatação. } \\
\text { Diurese e excreção de íon } \mathrm{Na+} \text { (sódio). }\end{array}$ \\
\hline $\begin{array}{l}\text { DA } 2 \text { (dopaminérgico tipo 2) } \\
\text { Pré-sináptico }\end{array}$ & Vasos & Vasodilatação. \\
\hline Pós-sináptico & Rins e supra-renais & Diminui a liberação de renina e aldosterona. \\
\hline $\begin{array}{l}\beta 1 \text { (beta 1) } \\
\text { Pós-sináptico }\end{array}$ & Coração & $\begin{array}{l}\text { Aumento da contratilidade cardíaca, fre- } \\
\text { qüência e velocidade de condução. }\end{array}$ \\
\hline $\begin{array}{l}\beta 2 \text { (beta 2) } \\
\text { Pós-sináptico }\end{array}$ & $\begin{array}{l}\text { Vasos } \\
\text { Coração }\end{array}$ & $\begin{array}{l}\text { Dilatação. } \\
\text { Aumento da freqüência e contratilidade } \\
\text { cardíacas, menos potente. }\end{array}$ \\
\hline $\begin{array}{l}\alpha 1 \text { (alfa 1) } \\
\text { Pós-sináptico }\end{array}$ & Vasos & $\begin{array}{l}\text { Vasoconstrição e aumento da pressão } \\
\text { arterial (ação direta). }\end{array}$ \\
\hline $\begin{array}{l}\alpha 2 \text { (alfa 2) } \\
\text { Pré-sináptico } \\
\text { Pós-sináptico }\end{array}$ & $\begin{array}{l}\text { Vasos } \\
\text { Coração } \\
\text { Vasos }\end{array}$ & $\begin{array}{l}\text { Inibição da liberação de noradrenalina } \\
\text { ("feed-back"). } \\
\text { Vasoconstrição e aumento da pressão arterial. }\end{array}$ \\
\hline
\end{tabular}

\begin{tabular}{|lll|}
\hline \multicolumn{2}{|c|}{ Tabela II - Doenças e condições que alteram a densidade dos receptores nas células efetoras } \\
\hline Doença ou Condição & Receptor Alterado & Alteração \\
\hline Insuficiência Cardíaca, Congestiva & Beta (coração) & Aumentado \\
Sepse & Alfa (fígado, sistema vascular) & Diminuído \\
Isquemia Miocárdica & Beta (coração) & Diminuído \\
& Alfa (coração) & Aumentado \\
Asma & Beta (pulmão, leucócitos) & Diminuído \\
Administração de Agonista & Alfa, Beta (coração, plaquetas, leucócitos) & Diminuído \\
Administração de Antagonista & Alfa, Beta (coração, plaquetas, leucócitos) & Aumentado \\
Hipotiroidismo & Beta (coração) & Diminuído \\
Hipertiroidismo & Beta (coração) & Aumentado \\
\hline
\end{tabular}

a farmacoterapia das drogas, em pacientes com choque circulatório. Fenômeno como "down regulation" (diminuição do número de receptores na superfície da célula) representa a perda de sensibilidade específica a um agonista ou, mesmo, ocorre por ação prolongada deste, como na insuficiência cardíaca congestiva, na asma com tratamento a longo prazo e na desnutrição grave subaguda ou crônica. Parece, tam- bém, existir uma "up regulation" (hiperexitabilidade) de ocorrência freqüiente em pacientes que suspendem o uso de betabloqueadores, após longo tempo de uso ${ }^{(4)}$.

Os efeitos das catecolaminas são dose dependentes, sendo que o aumento da liberação endógena dessas substâncias, em situações de estresse, ocupa os receptores, diminuindo os que estão disponíveis para interação com as drogas de administração exógena. 
O resultado da interação catecolamina e receptor é transmitido para os sistemas efetores, celulares através da ativação da adenilciclase e elevação da adenosina monofosfato, cíclica (AMPc), intracelular.

\section{CLASSIFICAÇÃO DAS CATECOLAMINAS}

Como já foi citado anteriormente, as catecolaminas exibem efeitos de acordo com a dose utilizada, podendo estimular receptores alfa, beta e dopa. Essa drogas são, então, classificadas em alfa adrenérgicas, beta adrenérgicas e dopaminérgicas ou mistas, de acordo com o predomínio de receptores sensibilizados. $\mathrm{Na}$ Tabela III, pode ser visualizado o grau e a capacidade de estimulação dos diversos receptores às diferentes catecolaminas.

\begin{tabular}{|lcccccc|}
\hline \multicolumn{7}{|l|}{ Tabela III - Principais catecolaminas e seus efeitos } \\
nos diversos receptores adrenérgicos \\
\hline \multicolumn{7}{|c|}{ Receptor } \\
Catecolamina & Dopa & $\beta 1$ & $\beta 2$ & $\alpha 1$ & $\alpha 2$ \\
\hline Norepinefrina & - & +++ & + & +++ & +++ \\
Epinefrina & - & +++ & +++ & +++ & +++ \\
Dopamina & +++ & +++++ & ++ & +++ & + \\
Dopexamina & +++ & + & $++/+++$ & - & - \\
Dobutamina & - & +++ & + & $-/+$ & - \\
Isoprenalina & - & +++ & +++ & - & - \\
\hline -l+ ou + estimulação relativa & & & \\
- - ausência de estimulação \\
\hline
\end{tabular}

\subsection{Dopamina}

A dopamina é o precursor imediato da noradrenalina $^{(6)}$. Trata-se de uma substância derivada da fenilalanina, agindo através da estimulação direta nos receptores beta $1 \mathrm{e}$, indiretamente, nos demais receptores, através da liberação de NA que, por sua vez, também estimula receptores beta 1 . Possui inúmeros efeitos, pois estimula todos os tipos de receptores, sendo estes dose dependentes (Tabela IV).

Por ser uma molécula polar, não atravessa a barreira hematoencefálica, não apresentando, assim, ação no sistema nervoso central (SNC) ${ }^{(7)}$. Possui vida média de 1,7 minutos, sendo metabolizada e inativada diretamente pela catecol-o-metil transferase (COMT) e monoamina oxidase (MAO), e parte transformada em noradrenalina e adrenalina. Os seus metabólitos são eliminados por via renal.

\subsubsection{Indicações}

As indicações principais da dopamina estão relacionadas aos estados de baixo débito com volemia controlada ou aumentada (efeito beta adrenérgico). Pelo fato de essa droga vasoativa possuir, em baixas doses, um efeito vasodilatador renal, é também indicada em situações nas quais os parâmetros hemodinâmicos estejam estáveis, porém com oligúria persistente (efeito dopaminérgico). Ela pode, também, ser utilizada em condições de choque com resistência periférica, diminuída (efeito alfa adrenérgico).

\subsubsection{Doses}

A diluição padrão é de cinco (5) ampolas em $200 \mathrm{ml}$ de solução (ringer simples ou lactato), soro fisiológico (SF 0,9\%), soro glicosado (SG 5\%) sendo somente incompatível com soluções alcalinas. Essa diluição apresentará uma concentração final da droga de $1 \mathrm{mg} / \mathrm{mL}$. A dopamina é disponível na forma de cloridrato de dopamina em ampolas com 50 e $200 \mathrm{mg}$ da droga. Deve ser utilizada sempre diluída e podemos usá-la de 2,5 a $20 \mu \mathrm{g} / \mathrm{kg} / \mathrm{min}$. A dose deve ser administrada de acordo com o efeito desejado e individualizada para cada paciente. Nós desenvolvemos, na Disciplina de Terapia Intensiva do Departamento de Cirurgia, Ortopedia e Traumatologia - FMRPUSP, uma tabela didática de uso rotineiro, que individualiza a dose programada em função do peso e da posologia desejada, para a administração de dopamina (Tabela V).

\subsubsection{Cuidados}

Deve ser utilizada somente para uso endovenoso com o cuidado de não haver extravasamento tissular, o que poderá acarretar uma intensa vasoconstrição local, com necrose tecidual. Os efeitos colaterais da dopamina incluem: náuseas, vômitos, arritmias (supraventriculares $4 \%$ e ventriculares 1 a $1,5 \%$ ) e agravamento da vasoconstrição pulmonar. Parece não haver uma interação medicamentosa, importante, com outras drogas, podendo ser associada a corticóides, catecolaminas e diuréticos.

\subsection{Dobutamina}

A dobutamina é uma droga simpatomimética sintética, com ação predominantemente beta 1 agonista, tendo sido desenvolvida em 1978, depois que a molécula da catecolamina foi modificada, na procura de uma droga que tivesse atividade inotrópica, se- 


\begin{tabular}{|c|c|c|c|}
\hline \multicolumn{4}{|c|}{ Tabela IV - Principais efeitos da dopamina, em função da dose administrada } \\
\hline Ação & $\begin{array}{l}\text { Doses baixas } \\
\leq 5 \mu \mathrm{g} / \mathrm{kg} / \mathrm{min} \\
\text { Efeito dopaminérgico } \\
\text { predominante }\end{array}$ & $\begin{array}{l}\text { Doses médias } \\
5-15 \mu \mathrm{g} / \mathrm{kg} / \mathrm{min} \\
\text { Efeito } \beta \text { (beta) } \\
\text { predominante }\end{array}$ & $\begin{array}{l}\text { Doses altas } \\
\geq 15 \mu \mathrm{g} / \mathrm{kg} / \mathrm{min} \\
\text { Efeito } \alpha \text { (alfa) } \\
\text { predominante }\end{array}$ \\
\hline Freqüência Cardíaca & Pouco modificada & Leve aumento inicial & Leve aumento inicial \\
\hline Débito Cardíaco & $\begin{array}{l}\text { Aumento } \\
\text { a) retorno venoso } \\
\text { b) resistências periféricas } \\
\text { c) efeito inotrópico + }\end{array}$ & $\begin{array}{l}\text { Aumento evidente } \\
\text { c) efeito inotrópico +++ }\end{array}$ & $\begin{array}{l}\text { b) estabilizada } \\
\text { c) diminuído às vezes } \\
\text { (vasoconstricção marcada) }\end{array}$ \\
\hline $\begin{array}{l}\text { Resistência Vascular, } \\
\text { Sistêmica }\end{array}$ & $\begin{array}{l}\text { Diminuição } \\
\text { (vasodilatação renal e } \\
\text { mesentérica) }\end{array}$ & Pouco modificada & Aumento \\
\hline Pressão Arterial & Geralmente inalterada & Aumento & Aumento evidente \\
\hline $\begin{array}{l}\text { Pressão telediastólica do VE } \\
\text { (PTDVE) }\end{array}$ & $\begin{array}{l}\text { Pouco modificada ou } \\
\text { levemente diminuída }\end{array}$ & Pouco modificada & Aumento \\
\hline Fluxo Sangüíneo Renal & Aumento & Pouco modificado & Diminuição \\
\hline Diurese & Aumento & Aumento & $\begin{array}{l}\text { Nenhum aumento ou } \\
\text { diminuição }\end{array}$ \\
\hline Risco de Arritmia & Escasso & Raro & Se PTDVE e PA aumentadas \\
\hline
\end{tabular}

\section{Tabela V - Esquema de administração de dopamina, utilizada pela Disciplina de Terapia Intensiva do Depar-} tamento de Cirurgia, Ortopedia e Tramautologia da FMRPUSP

DOPAMINA*

SG 5\% - $200 \mathrm{ml}$ (Retirar 50 dos $250 \mathrm{ml}$ do SG 5\%) + DOPAMINA - cinco (5) ampolas (50 ml = $50 \mathrm{mg})$

Diluição Final $=1 \mathrm{ml} / 1 \mathrm{mg}$

PESO $(\mathrm{kg})$ mcgotas/min (a ser infundido)

$\mathrm{mcg} / \mathrm{kg} / \mathrm{min}$ desejado

3

40

$40 \quad 7,2$

45

8,1

3

50

$$
55
$$$$
9,0
$$

9,9

10,8

60

65

$$
11,7
$$

12,6

13,5

14,4

15,3

16,2

17,1

18,0

\section{5}

12,0

13,5

15,0

16,5

18,0

19,5

21,0

22,5

24,0

25,5

27,0

28,5

100

$$
18,0
$$

30,0

7,5

18,0

20,3

22,5

24,8

27,0

29,3

31,5

33,8

36,0

38,3

40,5

42,8

45,0
10

24,0

27,0

30,0

33,0

36,0

39,0

42,0

45,0

48,0

51,0

54,0

57,0

60,0
12,5

30,0

33,8

37,5

41,3

45,0

48,8

52,5

56,3

60,0

63,8

67,5

71,3

75,0

* Obs: No caso de haver restrição hídrica, a diluição final será de $1 \mathrm{ml} / 2 \mathrm{mg}$ (utilizar dez (10) ampolas de DOPA (100 mg). Dividir o volume em $\mathrm{mcg} / \mathrm{min}$ da tabela por 2 . 
letiva, com pequeno efeito vascular periférico. Esta droga vasoativa possui baixa afinidade por receptores beta 2 e é quase desprovida de efeitos alfa adrenérgicos. Ao contrário da dopamina, a ação farmacológica da dobutamina não depende das reservas liberáveis de noradrenalina ${ }^{(8)}$. A dobutamina perde seu efeito hemodinâmico durante infusão prolongada, presumivelmente por causa da diminuição da atividade dos receptores adrenérgicos ("down regulation"), mas mantém o seu efeito hemodinâmico melhor que a dopamina, uma vez que esta depleta as reservas de noradrenalina do miocárdio ${ }^{(9,10)}$. A dobutamina possui vida média de dois (2) minutos, seu início de ação é rápido, não havendo, então, necessidade de dose de ataque. A sua excreção é renal ${ }^{(11)}$. Além disso, a dobutamina apresenta poucos efeitos sobre a FC, aumenta a contratilidade miocárdica e o índice cardíaco, não agindo sobre a resistência vascular, periférica, em doses médias.

\subsubsection{Indicações}

A droga é utilizada para melhorar a função ventricular e o desempenho cardíaco, em pacientes nos quais a disfunção ventricular acarreta diminuição no volume sistólico e no DC como, por exemplo, choque cardiogênico e insuficiência cardíaca, congestiva ${ }^{(7)}$. $\mathrm{O} \mathrm{VO}_{2}$ do miocárdio, sob o uso da dobutamina, é menor do que sob a ação de outras catecolaminas ${ }^{(12)}$. A estimulação dos betarreceptores provoca leve queda da pressão arterial (PA) por vasodilatação periférica. Há também aumento da velocidade de condução atrioventricular, o que limita seu uso na vigência de fluter ou fibrilação atrial ${ }^{(13)}$.

\subsubsection{Doses}

A dobutamina é disponível na forma de hidrocloridrato de dobutamina, em ampolas de $20 \mathrm{ml}$, com $250 \mathrm{mg}$ da droga. Dilui-se uma (1) ampola (250 mg) em $230 \mathrm{ml}$ de solução (exceto soluções alcalinas). A concentração final será de $1 \mathrm{mg} / \mathrm{ml}$. Sua utilização é sempre diluída, endovenosamente, em infusão contínua, em doses de 3 a $15 \mu \mathrm{g} / \mathrm{kg} / \mathrm{min}$, que deverá ser individualizada para cada paciente de acordo com o efeito hemodinâmico que se espera obter. O início da ação ocorre em dois (2) minutos, com efeito máximo em dez (10) minutos.

\subsubsection{Efeitos colaterais}

Os efeitos colaterais da dobutamina incluem: arritmias, dores de cabeça, ansiedade, tremores, aumentos ou reduções excessivas da PA.

\subsection{Noradrenalina (NA)}

A noradrenalina (NA) é o neurotransmissor do sistema nervoso simpático e precursor da adrenalina. A NA possui atividade tanto no receptor alfa, como beta 1 adrenérgico, com pouca ação sobre receptores beta $2^{(11)}$. Dependendo da dose utilizada, obtém-se aumento do volume sistólico, diminuição reflexa da FC e importante vasoconstrição periférica, com aumento da PA. A contratilidade e o trabalho cardíaco também aumentam se o aumento da pós-carga for tolerado pelo ventrículo. A noradrenalina é também um potente vasoconstritor visceral e renal, o que limita sua utilização clínica ${ }^{(14)}$. É também vasoconstritora sobre a rede vascular, sistêmica e pulmonar, e deve ser usada com prudência, em pacientes com hipertensão pulmonar.

\subsubsection{Indicações}

A noradrenalina é uma droga de eleição no choque séptico, cuja finalidade é elevar a PA em pacientes hipotensos, que não responderam à ressuscitação por volume e a outros inotrópicos menos potentes. Além disso, essa potente droga vasoativa é quase sempre utilizada durante as manobras da ressuscitação cardiopulmonar (RCP), como droga vasoconstritora. A droga é rapidamente eliminada do plasma após a sua administração intravenosa, com vida média de dois (2) a dois e meio (2,5) minutos, embora haja grande variação individual. A sua degradação é hepática e a eliminação renal.

\subsubsection{Doses}

Utilizam-se, normalmente, cinco (5) ampolas (2 mg) diluídas em $250 \mathrm{ml}$ de qualquer solução rotineira (exceto em soluções alcalinas), cuja concentração final será de $0,04 \mathrm{mg} / \mathrm{ml}$. A droga é disponível sob a forma de bitartarato de noradrenalina, sendo que a infusão endovenosa, contínua é, geralmente, iniciada em doses de 0,05 a $0,1 \mu \mathrm{g} / \mathrm{kg} / \mathrm{min}$, até que o efeito hemodinâmico desejado seja alcançado e não haja efeitos colaterais importantes. As doses administradas podem atingir um máximo de 1,5 a $2 \mu \mathrm{g} / \mathrm{kg} / \mathrm{min}$. Durante as manobras de RCP, podem-se usar doses de 0,1 a $0,2 \mathrm{mg} / \mathrm{kg}$, endovenosas ou intratraqueais, diluídas em $10 \mathrm{ml}$ de água destilada.

\subsubsection{Cuidados}

As infusões de NA devem ser administradas preferivelmente através de uma veia central, a PA 
deve ser monitorizada a cada quinze (15) minutos, principalmente durante o ajuste da dose. A função renal também deve ser monitorizada através de dosagens de uréia, creatinina e volume de diurese. Cuidados com necrose e escaras, no local da injeção intravenosa, devem ser prevenidos, evitando-se o extravasamento da droga. A infusão deve ser efetuada em veia de grosso calibre e a localização desta deve ser alterada, no mínimo, a cada doze (12) horas. A droga deve ser evitada em grávidas pelo seu efeito contrátil sobre o útero gravídico. A administração de altas concentrações também pode precipitar hipotensão acentuada, infarto do miocárdio ou hemorragia cerebral ${ }^{(11)}$. $\mathrm{O}$ uso da noradrenalina, em altas doses e por tempo prolongado, pode provocar graves lesões renais, cutâneas e mesmo cardíacas devido à vasoconstrição excessiva. No choque cardiogênico, o seu uso é limitado devido ao aumento do $\mathrm{VO}_{2}$ e aumento do trabalho cardíaco, provocado pelo incremento da pós-carga no miocárdio isquêmico ${ }^{(15)}$.

\subsection{Adrenalina}

A adrenalina é um hormônio endógeno, largamente produzido pela supra-renal e liberado em resposta ao estresse. Essa droga vasoativa é um potente estimulador alfa e beta adrenérgico, com notáveis ações sobre o miocárdio, músculos vasculares e outros músculos lisos, cujo efeito vasopressor é muito conhecido. O mecanismo da elevação da PA, causado pela adrenalina, é devido a uma ação direta no miocárdio, com aumento da contração ventricular (inotropismo positivo), um aumento da freqüência cardíaca (cronotropismo positivo) e uma vasoconstrição em muitos leitos vasculares (arteríolas da pele, rins e vênulas). Seus efeitos são diferentes, quando a droga é administrada por infusão intravenosa ou injeção subcutânea, sendo que a absorção por esta via é mais lenta devido à ação vasoconstritora, local, causada pela adrenalina ${ }^{(11)}$.

No miocárdio, a adrenalina exerce uma ação direta sobre receptores beta 1 do músculo, células do marcapasso e tecido condutor. A FC e o ritmo quase sempre são alterados. A sístole torna-se mais curta e potente. Aumentam o débito e o trabalho cardíacos, bem como o $\mathrm{VO}_{2}$ do miocárdio. O período refratário do músculo ventricular, por sua vez, diminui, predispondo-o ao aparecimento de arritmias. Na musculatura lisa, sua ação predominante é de relaxamento através da ativação de receptores alfa e beta adrenérgicos. A droga exerce, também, importantes efeitos na musculatura brônquica (broncodilatação) pela interação com receptores beta 2 do músculo liso, bronquial, combinada à inibição da degranulação de mastócitos. Esse efeito é determinado largamente pela quantidade de adrenalina circulante, visto que a inervação simpática do músculo liso, brônquico é escassa. A droga também eleva as concentrações de glicose (aumento da neoglicogênese e inibição da secreção de insulina) e do lactato sérico. Pode, também, provocar hipopotassemia e aumento dos níveis de ácidos graxos livres.

A absorção da adrenalina, quando administrada por via subcutânea, é lenta. Todavia, é mais rápida, quando usada por via intravenosa ou intramuscular. As ações se restringem ao trato respiratório, quando a droga é nebulizada, podendo, entretanto, ocorrerem reações sistêmicas, acompanhadas de arritmias. A sua metabolização é hepática, sendo que sua vida média é de, aproximadamente, três (3) minutos.

\subsubsection{Indicações}

As principais indicações da adrenalina incluem estados de choque circulatório que não respondem às outras catecolaminas menos potentes, em particular no choque cardiogênico, quando de uso combinado com agentes redutores da pós-carga. Recomenda-se esta droga no tratamento de brocoespamos severos, na dose de $0,01 \mathrm{mg} / \mathrm{kg}$ até $0,3 \mathrm{mg}$, a cada vinte (20) minutos. Endovenosamente, é indicada no tratamento da anafilaxia e, durante as manobras de ressuscitação cardiopulmonar, é o agente farmacológico de efeito vasoconstritor mais eficaz.

\subsubsection{Doses}

A adrenalina é disponível numa variedade de formulações para as diferentes indicações clínicas e vias de administração. A droga é instável, em solução alcalina, e é oxidada, quando exposta ao ar ou à luz. A sua apresentação mais comumente encontrada são ampolas de $1 \mathrm{ml}$, com $1 \mathrm{mg}$ da droga (1:1000). Em infusão contínua, costuma-se diluir a droga em SF $0,9 \%$ ou SG $5 \%$. Utilizam-se cinco (5) ampolas (5 mg) em $250 \mathrm{ml}$ de solução, cuja concentração será de $20 \mu \mathrm{g} / \mathrm{ml}$. O início da administração é efetuado com doses de 0,05 a $0,1 \mu \mathrm{g} / \mathrm{kg} / \mathrm{min}$, que podem ser aumentadas, progressivamente, até que se obtenha o efeito hemodinâmico desejado. Doses maiores que $2 \mu \mathrm{g} / \mathrm{kg} / \mathrm{min}$ devem ser evitadas. Durante as manobras de RCP, as doses padronizadas são de 0,5 a $1 \mathrm{mg}$ (endovenoso ou endotraqueal, diluídas em 10-20 ml de água destilada) repetidas a cada cinco a dez (5-10) minutos. 


\subsubsection{Cuidados}

A adrenalina deve ser administrada com o auxílio de bombas de infusão, preferivelmente, através de uma veia central (de grosso calibre), uma vez que o extravasamento da droga pode provocar lesões cutâneas importantes. Além disso, há as reações desagradáveis como tremor, ansiedade, tensão, cefaléia, vertigem, dificuldade respiratória, hipertensão grave, hemorragia cerebral, arritmias (principalmente ventriculares) e angina pectoris.

\subsection{Isoproterenol}

O isoproterenol é uma catecolamina sintética, de estrutura semelhante à adrenalina. É um potente agonista beta adrenérgico, com afinidade muito baixa pelos receptores alfa. Portanto, exerce efeitos potentes no sistema cardiovascular, com aumento da contratilidade, freqüência e velocidade de condução do estímulo elétrico, cardíaco. Observa-se um aumento no débito cardíaco e no $\mathrm{VO}_{2}$ do miocárdio ${ }^{(16)}$. A estimulação dos receptores beta adrenérgicos resulta num relaxamento da musculatura lisa, vascular, ao mesmo tempo em que a resistência vascular, sistêmica e a pressão diastólica caem.

O músculo liso da via aérea, brônquica e vascular, pulmonar também são relaxados pelo isoproterenol, ocasionando uma diminuição da resistência vascular, pulmonar e reversão de broncoespamos. Esse efeito pode levar a situações de aumento do "shunt" intrapulmonar por alteração da relação ventilação/perfusão, com predomínio da perfusão, agravando a hipoxemia arterial. $\mathrm{O}$ isoproterenol não produz o mesmo grau de hiperglicemia que a adrenalina, provavelmente porque a estimulação beta adrenérgica aumenta a liberação de insulina. A droga pode ser absorvida, quando administrada por via parenteral ou na forma de aerossol, sendo metabolizada, primariamente, no fígado e em outros tecidos pela COMT, possuindo uma meia-vida de cerca de dois (2) minutos.

\subsubsection{Indicações}

Principalmente nas síndromes de baixo débito com pressões de enchimento elevadas e resistência periférica e pulmonar também elevadas (choque cardiogênico). É também indicado para tratar os casos de bradicardia com repercussão hemodinâmica (bloqueios), como medida temporária até que uma terapia definitiva (marcapasso) seja utilizada.

\subsubsection{Doses}

O isoproterenol é disponível para utilização na forma de cloridrato de isoproterenol (indisponível no Brasil, do ponto de vista comercial), podendo, contudo, ser manipulado em ampolas de $1 \mathrm{ml}$, com $1 \mathrm{mg}$ da droga ativa. Utilizam-se cinco (5) ampolas (5 mg), em $250 \mathrm{ml}$ de solução salina ou glicosada, a $5 \%$, o que resulta numa concentração final de $20 \mu / \mathrm{ml}$. Em infusão venosa, contínua, inicia-se o isoproterenol em doses de 0,005 a $0,1 \mu \mathrm{g} / \mathrm{kg} / \mathrm{min}$, podendo atingir-se, no máximo, $2,0 \mu \mathrm{g} / \mathrm{kg} / \mathrm{min}$.

\subsubsection{Efeitos colaterais}

O seu efeito colateral mais grave reside na sua capacidade de produzir arritmias cardíacas de natureza supraventricular (taquiarritmias) ou ventriculares (ectopias severas) e hipotensão. A angina e o infarto do miocárdio podem resultar da ação desfavorável do isoproterenol, no aumento da demanda de $\mathrm{O}_{2}$, relativa ao suprimento deste na musculatura cardíaca. A droga deve, desse modo, ser evitada em coronariopatas. Sinais e sintomas como palpitações, cefaléia e rubor de pele são também reações colaterais comuns.

\subsection{Dopexamina}

Recentemente desenvolvida na Europa e introduzida para uso clínico a partir de 1980, a dopexamina é uma catecolamina sintética com atividade dopaminérgica e beta 2 agonista, com fraco efeito beta 1 adrenérgico e ausência de efeitos em receptores alfa. Quando comparada à dopamina, a dopexamina tem menor potência ( $1 / 3$ da ação) ao estimular receptores dopaminérgicos, ao passo que seus efeitos beta 2 são cerca de sessenta (60) vezes mais potentes ${ }^{(3)}$. Assim, o estímulo de receptores beta resulta em aumento no débito cardíaco (atividade inotrópica positiva), queda da resistência vascular, sistêmica e aumento no volume urinário e na excreção de sódio por estimulação dopaminérgica. Além disso, a droga potencializa os efeitos da noradrenalina endógena, pelo bloqueio da recaptação da mesma. A sua meia-vida é muito curta, o que permite ajustes freqüentes e progressivos da dose.

\subsubsection{Indicações}

A dopexamina pode ser utilizada no tratamento da insuficiência cardíaca, aguda (secundário a infarto agudo do miocárdio (IAM), insuficiência cardíaca congestiva (ICC), refratária e nos pacientes 
em pós-operatório de cirurgia cardíaca, que evoluem com baixo débito, com algumas vantagens em relação à dopamina (menor atividade beta 1 e ausência de atividade alfa) e à dobutamina. Além disso, a dopexamina pode, também, ser utilizada no choque séptico, em associação com a noradrenalina, na tentativa de prevenção da insuficiência renal, aguda e no incremento do fluxo mesentérico e da perfusão gastrintestinal, evitando-se, assim, a translocação bacteriana.

\subsubsection{Doses}

As ampolas de dopexamina têm concentração de $50 \mathrm{mg}$ da droga, sendo que esta deve ser diluída em SG 5\% ou SF 0,9\% (5 ampolas em $250 \mathrm{ml}$ de solução). Inicia-se a dopexamina em doses de 0,5 a $1 \mu \mathrm{g} / \mathrm{kg} / \mathrm{min}$, devendo ser administrada de acordo com o efeito hemodinâmico ideal desejado. As doses médias habituais são de 0,5 a $6,0 \mu \mathrm{g} / \mathrm{kg} / \mathrm{min}$, sendo que o seu uso é exclusivamente feito por via endovenosa.

\subsubsection{Cuidados}

Não deve ser administrada a pacientes hipovolêmicos. Náuseas, vômitos, arritmias e angina "pectoris" podem ocorrer quando da sua utilização.

\subsection{Amrinone}

A amrinone é um derivado bipiridínico com efeito cardiotônico e inotrópico. O seu mecanismo de ação está ligado à inibição potente e seletiva da fosfodiesterase FIII, aumentando a concentração intracelular de AMP cíclico, nas células cardíacas. As bipiridinas também parecem aumentar a disponibilidade intracelular de cálcio, o que incrementa a função contrátil do miocárdio ${ }^{(17)}$. Ocorre, também, um aumento na concentração de AMP cíclico das células musculares, lisas, dos vasos sangüíneos, o que promoveria uma vasodilatação venosa e arteriolar (periférica e pulmonar) com diminuição da pós-carga. Parece, então, que o aumento no débito cardíaco, promovido pela amrinone, advém da interação dessas duas ações: ação inotrópica direta e relaxamento do tônus vascular. Sabe-se que a potência dessa droga no tecido vascular é de dez (10) a cem (100) vezes maior que sua ação inotrópica. A amrinone é eliminada por excreção renal, possuindo uma meia vida de três (3) a seis (6) horas, com eliminação mais lenta, observada em pacientes com insuficiência cardíaca, congestiva, o que pode, quando utilizada em infusão contínua, resultar num aumento progressivo da droga, após várias horas ${ }^{(18)}$.

\subsubsection{Indicações}

A amrinone é particularmente benéfica na terapêutica da insuficiência cardíaca refratária e grave, vez que ocorre uma redução na pós-carga e um aumento na contratilidade cardíaca, sem aumentar o $\mathrm{VO}_{2}$ do miocárdio.

\subsubsection{Doses}

O lactato de amrinone (Inocor) é disponível em solução de $100 \mathrm{mg}$, em frascos de $20 \mathrm{ml}$. Este frasco é diluído em SF $0,9 \%$ ou $0,45 \%$. Utilizam-se duas (2) ampolas (200 mg) diluídas em $250 \mathrm{ml}$ de SF, cuja concentração final será de $800 \mu \mathrm{g} / \mathrm{ml}$. A posologia recomendada é inicialmente de $0,75 \mathrm{mg} / \mathrm{kg}$, durante três (3) a cinco (5) minutos, seguida por uma infusão intravenosa, contínua de 5 a $10 \mu \mathrm{g} / \mathrm{kg} / \mathrm{min}$. A concentração plasmática ideal é observada em poucos minutos, após o início da infusão. A duração da terapêutica em geral é de quarenta e oito (48) a setenta e duas (72) horas.

\subsubsection{Cuidados}

A meia-vida da amrinone é relativamente longa, restringindo-se o seu uso em doentes com disfunção renal grave. Não deve ser utilizada em solução glicosada. A droga pode produzir trombocitopenia reversível, em aproximadamente $4 \%$ dos pacientes. Hipotensão arterial, severa e arritmias ventriculares, que obrigam a suspensão da infusão, podem ocorrer.

\section{VASODILATADORES}

A falência circulatória aguda possui muitas etiologias, porém os mecanismos determinantes são: a diminuição do volume circulante, a diminuição do DC e a diminuição da resistência vascular periféri$\mathrm{ca}^{(1)}$. O uso de drogas com ação vasodilatadora é útil nos casos em que a reposição volêmica adequada e a otimização do DC com os agentes inotrópicos, já mencionados, não reverteram a condição de baixo débito, persistente. Isso acontece, principalmente, nos casos de choque cardiogênico pós IAM, nos quais existe um aumento nas pressões de enchimento ventricular, associadas a incremento na resistência vascular, periférica (pós-carga) ${ }^{(19)}$. Na falência cardíaca, aguda o fator determinante para o incremento do DC é a resistência ao esvaziamento do ventrículo esquerdo. Reflexamente à falência circulatória, existe uma estimulação alfa adrenérgica, generalizada, com conseqüente 
aumento na resistência periférica, total, cujo resultado será o aumento da pressão arterial e a redução do DC. $\mathrm{O} \mathrm{VO}_{2}$ do miocárdio aumenta proporcionalmente à tensão na parede ventricular. A pressão de enchimento ventricular, aumentada, predispõe à hipertensão pulmonar com grande risco de desenvolvimento de edema agudo de pulmão. Dessa forma, com a diminuição simultânea da pressão de enchimento ventricular esquerdo, da resistência periférica total (com redistribuição do fluxo sangüíneo de áreas não essenciais para áreas nobres) e da impedância ao esvaziamento ventricular esquerdo, o uso de vasodilatadores está indicado, ocasionando uma melhor performance cardíaca, com incremento no débito. Conseqüentemente, a pressão capilar, pulmonar seria reduzida com benefícios imediatos.

O uso de vasodilatadores não altera significativamente a frequiência cardíaca, visto que há um aumento do volume sistólico, em resposta à queda da resistência vascular, sistêmica, induzida por essas drogas $^{(3)}$. Os vasodilatadores podem ser classificados, genericamente, de acordo com seu sítio de ação em venodilatadores (nitratos e nitroglicerina), arteriolodilatadores (hidralazina) e de ação mista (nitroprussiato de sódio, prazozin, inibidores da ECA e clorpromazina). Particularmente, o vasodilatador mais utilizado em terapia intensiva é o nitroprussiato de sódio.

\subsection{Nitroprussiato de sódio}

O nitroprussiato de sódio é um vasodilatador misto, com efeitos sobre os territórios arterial e venoso. Age diretamente na musculatura lisa, vascular, através da interação com grupos intracelulares de sulfidrila, inibição do transporte de cálcio e alteração dos nucleotídeos cíclicos, intracelulares. Não apresenta efeito direto sobre as fibras musculares cardíacas, sendo seu incremento no DC devido à ação vasodilatadora. $\mathrm{O}$ nitroprussiato de sódio promove uma redução no $\mathrm{VO}_{2}$ do miocárdio. $\mathrm{O}$ fluxo sangüíneo renal e a taxa de filtração glomerular são mantidos e a secreção de renina, pelo organismo, é aumentada ${ }^{(7)}$. A droga promove, então, diminuição da resistência periférica, total, diminuição da PA, pouca alteração da FC e diminuição da resistência vascular, pulmonar, sendo rapidamente metabolizada e convertida em tiocianato através de reação catalisada pela rodonase no fígado. O tiocianato pode ser, de forma lenta e incompleta, oxidado a cianeto nos eritrócitos, pela ação da tiocianatoxidase. O tiocianato é eliminado exclusivamente pelos rins, em média, após três (3) a quatro (4) dias. Outro metabólito ativo da droga é o óxido nítrico, que parece ser o responsável pela ação vasodilatadora, através da ativação da guanilato ciclase, levando à formação de GMPc e à vasodilatação ${ }^{(20)}$. O nitroprussiato de sódio é uma molécula instável, que sofre decomposição em condições alcalinas e quando exposto à luz. Sua ação ocorre segundos após a infusão ser iniciada, sendo seu efeito máximo alcançado em dois (2) minutos e, quando interrompida, seus efeitos são rapidamente revertidos à medida em que a substância vai sendo metabolizada.

\subsubsection{Indicações}

Indicado no tratamento das emergências hipertensivas e como droga auxiliar nos estados de choque circulatório, com pressões de enchimento ventricular e resistência periférica aumentadas (situações em que se desejam reduções a curto prazo da pré-carga e/ou pós-carga cardíacas).

\subsubsection{Doses}

O nitroprussiato de sódio é utilizado em infusão endovenosa, contínua e, exclusivamente, em doses que variam de 1 a $5 \mu \mathrm{g} / \mathrm{kg} / \mathrm{min}$. As doses necessárias para se obter uma resposta adequada devem ser tituladas e são variáveis, dependentes da idade do paciente e do grau de hipotensão desejado ${ }^{(21)}$. A duração da terapêutica não deve exceder três (3) a quatro (4) dias. Dispõe-se, para utilização, de ampolas com 50 $\mathrm{mg}$ da droga, normalmente diluídas em $2 \mathrm{ml}$ de solvente e adicionadas a $250 \mathrm{ml}$ de SG $5 \%$, com concentração final de $200 \mathrm{mg} / \mathrm{ml}$. Como existe uma sensibilidade da substância à luz, apenas soluções recentes (no máximo seis (6) horas após o preparo) devem ser utilizadas, e o frasco, assim como o equipo, devem ser envoltos com material opaco.

\subsubsection{Efeitos colaterais}

As intoxicações pelo cianeto e tiocianato podem ocorrer, quando se usam doses superiores a $5 \mu \mathrm{g} / \mathrm{kg} / \mathrm{min}$, por tempo prolongado. Parece que a toxicidade desses metabólitos é proporcional à velocidade de infusão e não à quantidade total de nitroprussiato de sódio, administrada. A intoxicação pelo cianeto leva ao bloqueio da respiração aeróbica, celular, promovendo acidose metabólica, sendo, no entanto, um evento de ocorrência rara. Constituem-se sinais de intoxicação 
pelo tiocianato: náuseas, fraqueza, espasmos musculares, confusão mental, cefaléia, diarréia, e taquicardia. Esses efeitos são minimizados logo que a infusão da droga é interrompida ou sua velocidade de eliminação aumentada. A droga deve ser utilizada com prudência em pacientes com hepatopatias e nefropatias, e os níveis plasmáticos de tiocianato devem ser monitorizados, não excedendo $10 \mathrm{mg} / \mathrm{dl}$. A meia-vida do tiocianato é de uma (1) semana e o tratamento da intoxicação consiste na administração de hidroxicobalamina e diálise.

\section{CONCLUSÃO}

Os estados de baixo débito, associados à disfunção celular, grave são de ocorrência relativamente comum nas unidades de terapia intensiva. O emprego das drogas vasoativas é de importância vital para a reversão desta situação, melhorando o prognóstico e a sobrevida dos pacientes. Essas drogas possuem, em geral, ação rápida e potente, porém seu índice terapêutico é baixo, devendo ser administradas mediante adequada monitorização hemodinâmica e laboratorial.

OSTINI FM et al. The use of vasoactives drugs in the intensive care unit. Medicina, Ribeirão Preto, 31: 400-411, july/sept. 1998.

ABSTRACT: The authors present a reviewed and updated description of vasoactives agents available for use in the critically ill patient. Furthermore, this paper describes the hemodynamic effects of these drugs in order to understand the guidelines of its use in the intensive care unit.

UNITERMS: Catecholamines. Vasodilator Agents. Vasoconstrictor Agents. Intensive Care Units.

\section{REFERÊNCIAS BIBLIOGRÁFICAS}

1 - ARAÚJO S. Drogas vasoativas. In: TERZI RGG \& ARAÚJO S. Técnicas básicas em UTI, $2^{a}$ ed., Manole, São Paulo, cap. 11, p. 215-232, 1992.

2 - SHOEMAKER WC. Diagnoses and treatment of the shock syndromes. In:SHOEMAKER WC et al. Textbook of critical care, $3^{\mathrm{a}}$ th. ed., W. B. Saunders, Philadelphia, Pennsylvania, cap. 13, p. 85-102, 1995.

3 - KASINSKI N et al. Drogas vasoativas. In: KNOBEL E. Condutas no paciente grave, Ateneu, São Paulo, cap. 12, p. 120-141, 1994.

4 - MÁTTAR JA. Catecolaminas e suporte hemodinâmico. In: $1^{\circ}$ Simpósio Internacional de UTI Geral - Temas Nacionais, São Paulo, p. 66-70, 1993.

5 - ZARITSKY A. Ontogenetic considerations in the pharmacoterapy of shock. In: CHERNOW B \& SHOEMAKER WC. Critical care: State or the art, Society of Critical Care Medicine, Fullerton, v. 7, p. 485-534, 1986.

6 - BRAUNWALD E. Agentes não glicosídicos inotrópicos. In: BRAUNWALD E. Tratado de medicina cardiovascular. $4^{\text {a }}$ ed, Roca, São Paulo, cap. 17, p. 538 - 544, 1996.

7 - JORGE SA et al. Planilha de estudo de drogas vasoativas em terapia intensiva. Rev Bras Ter Intensiva 1: 106-111, 1989.

8 - RUFFOLO Jr RR et al. Alpha and beta adrenergic effects of the stereoisomers of dobutamine. J Pharmacol Exp Ther 219: 447-452, 1981.
9 - UNVERFERTH DV et al. Tolerance to dobutamine after a 72 hour continuous infusion. Am J Med 69: 262-266, 1980.

10 - MAC CANNEL KL et al. Haemodynamic responce to dopamine and dobutamine infusions as a function of duration of infusion. Pharmacology 26: 29-39, 1983.

11 - HOFFMAN BB \& LEFKOWITZ RJ. Catecolaminas, drogas simpatomiméticas e antagonistas dos receptores adrenérgicos. In: GOODMAN L \& GILMAN A. As bases farmacológicas da terapêutica, $9^{\mathrm{a}}$ ed., McGraw-Hill Interamericana, México, cap. 10, p. 146-158, 1996.

12 - HANNEMANN L. Comparison of dopamine to dobutamine and norepinephrine for oxygen delivery and uptake in septic shock. Crit Care Med 23:1962-1970, 1995.

13 - GUERRA JB, QUEIROZ FP \& FEITOSA GS. Vasodilatores - anti-hipertensivos. In: ZANINI AC \& OLGA S. Farmacologia aplicada. $4^{\mathrm{a}}$ ed., Atheneu, São Paulo, cap. 12, p. 165-182, 1989.

14 - CHERNOW B. Abordagem farmacológica do doente grave. $2^{a}$ ed., Laboratório Lilly, São Paulo, p. 3-27, 1994. Monografia.

15 - FARMER JA. Cardiogenic shock. In: CIVETA, JM; TAYLOR, RW \& KIRBY, RR, eds. Critical care, $2^{a}$ ed., J. B. Lippincott, Philadelphia, Pennsylvania, cap. 85, p. 1129-1139, 1992.

16 - WORTHLEY LI et al. Conparison of dopamine, dobutamine and isoproterenol in the treatment of shock. Intensive Care Med 11: 13-19, 1985.

17 - ZANNAD F; JUILLERE Y \& ROYER RJ. The effects of amrinone on cardiac function, oxygen consumption and lactate production of na isolated, perfused working Guinea pig heart. Arch Int Pharmacodyn Ther 263: 264-271, 1984. 
18 - EDELSON $\mathrm{J}$ et al. Pharmacokinetics of the bipyridines amrinone and milrinone. Circulation 73:145-152, 1986. Suppl 3.

19 - RUDE RE. Pharmacologic support in cardiogenic shock. Adv Shock Res 10: 35-49, 1983.

20 - OATES JA. Fármacos anti-hipertensivos e a terapia farmacológica da hipertensão. In: GOODMAN L \& GILMAN A. As bases farmacológicas da terapêutica. $9^{\mathrm{a}}$ ed., McGraw-Hill Interamericana, México, cap. 33, p. 584-585, 1996.
21 - MÁTTAR JA. Drogas vasoativas. In: Anais do Simpósio de Avanços em Terapia Intensiva Adulto e Pediátrica, São Paulo, p. 225-226, 1994.

Recebido para publicação em 04/03/98

Aprovado para publicação em 13/05/98 